\title{
Pathophysiological Role of Neuroinflammation in Neurodegenerative Diseases and Psychiatric Disorders
}

\author{
Heeok Hong ${ }^{1}$, Byung Sun Kim ${ }^{2,3}$, Heh-In Im ${ }^{2,3}$ \\ ${ }^{1}$ Department of Medical Science, Konkuk University School of Medicine, Seoul, Korea \\ ${ }^{2}$ Convergence Research Center for Diagnosis, Treatment and Care System of Dementia, Korea Institute of Science and Technology (KIST), Seoul, Korea \\ ${ }^{3}$ Department of Neuroscience, Korea University of Science and Technology (UST), Daejeon, Korea
}

Brain diseases and disorders such as Alzheimer disease, Parkinson disease, depression, schizophrenia, autism, and addiction lead to reduced quality of daily life through abnormal thoughts, perceptions, emotional states, and behavior. While the underlying mechanisms remain poorly understood, human and animal studies have supported a role of neuroinflammation in the etiology of these diseases. In the central nervous system, an increased inflammatory response is capable of activating microglial cells, leading to the release of pro-inflammatory cytokines including interleukin (IL)- $1 \beta$, IL-6, and tumor necrosis factor- $\alpha$. In turn, the pro-inflammatory cytokines aggravate and propagate neuroinflammation, degenerating healthy neurons and impairing brain functions. Therefore, activated microglia may play a key role in neuroinflammatory processes contributing to the pathogenesis of psychiatric disorders and neurodegeneration.

Keywords: Inflammation; Brain Diseases; Microglia; Cytokines

- Grant Support: This work was supported by the National Research Council of Science \& Technology (NST) grant by the Korean government (MSIP) (No. CRC-15-04-KIST).

- Conflict of Interest: No potential conflict of interest relevant to this article was reported.

\section{INTRODUCTION}

Today, a growing number of people worldwide have psychiatric disorders and neurodegenerative diseases, characterized by abnormal thoughts, emotions, behaviors, and social communication. Despite decades of research, however, the etiologies of these afflictions remain poorly understood. Inflammation in the peripheral nervous system and the central nervous system (CNS), termed neuroinflammation, is believed to be one of the causes underlying these disorders. Numerous studies have proposed that inflammatory dysfunctions are associated with psy- chiatric disorders and neurodegeneration in both animal models and human patients [1-3]. Microglial activation has also been linked with brain diseases [4]. Microglia are CNS-resident immune cells activated in response to brain injury [5]. Microglial activation can induce the release of pro-inflammatory cytokines including interleukin (IL)-1 $\beta$, IL-6, and tumor necrosis factor (TNF)- $\alpha$, leading to neuronal damage and loss [6,7].

In this review, we summarize and discuss the potential roles of neuroinflammation in the etiology of diseases and disorders including Alzheimer disease, Parkinson disease, depression, autism spectrum disorder (ASD), addiction, and schizophrenia.
Corresponding author: Heh-In Im (iD http://orcid.org/0000-0002-4763-5009 Convergence Research Center for Diagnosis, Treatment and Care System of Dementia, Korea Institute of Science and Technology (KIST), 5 Hwarang-ro 14-gil, Seongbuk-gu, Seoul 02792, Korea

E-mail: him@kist.re.kr / Tel: +82-2-958-6961 / Fax: +82-2-958-6937

Submitted: April 19, 2016 / Accepted after revision: May 2, 2016
This is an Open Access article distributed under the terms of the Creative Commons Attribution Non-Commercial License (http://creativecommons.org/licenses/by-nc/4.0/) which permits unrestricted non-commercial use, distribution, and reproduction in any medium, provided the original work is properly cited. 


\section{NEURODEGENERATIVE DISEASES}

\section{Alzheimer Disease}

Dementia, the severe loss of intellectual abilities, affects over 46 million people worldwide [8]. Dementia has many origins, among which Alzheimer disease (AD) is the major cause.

$\mathrm{AD}$ is characterized by progressive loss of memory. The underlying mechanism is believed to be neurodegeneration caused by production and accumulation of $\beta$-amyloid (A $\beta$ ) peptides in the brain [9]. Previous studies have proposed that $A \beta$ deposition begins a cascade of reactions resulting in synaptic dysfunction, neuronal damage, and ultimately, neurodegeneration $[10,11]$, suggesting that $A \beta$ accumulation likely plays an important role in the pathophysiological process of $\mathrm{AD}$. Indeed, a recent study reported a potential relationship between $A \beta$ deposits and $\mathrm{AD}$-related neurodegeneration [12]. However, the findings of clinical and preclinical studies have been inconsistent, suggesting that the etiology of $\mathrm{AD}$ is not yet precisely understood.

Interestingly, innate immune activation has been considered a major component of age-related neurodegenerative diseases including $\mathrm{AD}[13,14]$. Inflammatory responses and pro-inflammatory mediators have been found to be capable of inducing neurodegeneration, resulting in neuronal loss and brain injury. Microglia are innate immune cells in the CNS that mediate inflammatory responses to pathogens and injury by inducing release of pro-inflammatory cytokines. In response to innate immune activation, microglia-derived pro-inflammatory cytokines, including TNF- $\alpha$, aggravate and propagate inflammation throughout brain. These pro-inflammatory factors may induce degeneration of normal neurons through upregulation of nuclear factor-kappa B, mitogen-activated protein kinase, and cJun N-terminal kinase [15].

\section{Parkinson Disease}

Parkinson disease (PD) is a chronic and progressive movement disorder marked by muscular rigidity, tremor, and bradykinesia [16-18]. The incidence and prevalence of PD increase with age and are consistently higher in men than in women [19].

$\mathrm{PD}$ is triggered by the reduction of dopamine, a brain neurotransmitter involved in control of movement, caused by the progressive loss of dopaminergic neurons in the substantia nigra pars compacta (SNpc) [20]. To date, studies have failed to elucidate the precise pathophysiological mechanisms underlying SNpc dopaminergic neurodegeneration in PD.
One of the pathological hallmarks of PD is chronic neuroinflammation [20]. Glial cell activation is a common feature in patients with PD and animal models of PD, and microglia and astrocytes are thought to play critical roles in the neuroinflammatory processes associated with PD [18]. It has been suggested that activated microglia may be beneficial to the host in the early phase of neurodegeneration in PD [11], but excessive activation of microglia leads to the elevated expression of pro-inflammatory mediators such as TNF- $\alpha$, IL- $1 \beta$, IL- 6 , and interferon- $\gamma$. These pro-inflammatory mediators may rapidly induce the degeneration of SNpc dopaminergic neurons [11,21]. Additionally, pro-inflammatory mediators released upon microglial activation can activate astrocytes, which in turn play a role in the neuroinflammatory processes in PD [22]. Overall, these studies suggest that microglia- and astrocyte-mediated inflammatory responses contribute to the pathophysiology of PD through the neurodegeneration of $\mathrm{SNpc}$ dopaminergic neurons.

\section{NEUROPSYCHIATRIC DISORDERS}

\section{Depression}

Major symptoms of depression include lack of enthusiasm, sadness, feelings of guilt, low self-worth, and disturbed sleep, all of which contribute to poor functioning in daily life through abnormal cognitive, emotional, and physical behaviors [23]. The World Health Organization estimates that approximately 350 million people worldwide suffer from depression, and nearly 1 million lives are lost yearly due to suicide [23].

Though depression is a common mental disorder, the etiology of this disorder is unclear. Animal and human studies have shown that chronic inflammation is frequently associated with the development of depression. For instance, patients with inflammatory disorders often reveal depressive symptoms [24]. This comorbid relationship is bidirectional, as patients with depressive disorder display increased serum levels of IL- $1 \beta$, IL- 6 , IL-8, and TNF- $\alpha$ [25]. In another study, expression of IL-6 and TNF- $\alpha$, but not IL-1 $\beta$, was elevated in depressed subjects [26]. Furthermore, increased expression of these pro-inflammatory mediators was observed in postmortem examination [27].

It has been proposed that the inflammatory processes in depression induce alterations of immune regulation in the CNS. Activation of the peripheral immune system leads to increased expression of cytokines that are actively transported into the CNS and stimulate microglia and astrocytes, which in turn produce cytokines through a feedback mechanism. As such, mi- 
croglia and astrocytes have been proposed as potential mediators of inflammatory alterations in depression [28].

Stress is known to contribute to the development of depression, and several studies suggest that stress is related to the activation of microglia $[29,30]$. For instance, stress can cause abnormal activation of microglia related to the increase in the production of inflammatory mediators such as IL-1 $1 \beta$, IL- 6 , and TNF- $\alpha[7,31,32]$. In addition, antidepressant drugs such as selective serotonin reuptake inhibitors and serotonin and norepinephrine reuptake inhibitors reduce microglial activation and inhibit inflammatory responses $[33,34]$.

Overall, these findings indicate that the activation of microglia is a potential effector of abnormally increased neuroinflammation in depression. However, the association between abnormal glial activation and depression in humans requires validation from clinical studies [35].

\section{Autism Spectrum Disorder}

ASD is a group of neurodevelopmental disorders characterized by language and intelligence deficits, repetitive behavior, and social communication disability [2]. The pathogenesis of ASD is poorly understood, but recent studies indicate that ASD is associated with immune dysfunction and brain inflammation [13,36].

Postmortem studies show that the number of microglial cells in patients with ASD is higher than in healthy individuals [37], and microglial activation is increased in patients with ASD $[38,39]$. In a study using lipopolysaccharide stimulation to induce the production of inflammatory mediators in pregnant mice, offspring exhibited increased microglia number and autistic symptoms, suggesting a causal link between inflammation and ASD [40,41]. In addition, increased pro-inflammatory cytokines are associated with hippocampal and cerebral damage in virus-infected neonatal rat models of autism [42].

These findings suggest that inflammation may be the origin of symptoms in ASD, and microglia-mediated dysregulation of the inflammatory response may contribute to the pathophysiology of ASD. Further studies focusing on the link between microglial activation and neuroinflammatory processes could help clarify the etiology of ASD.

\section{Addiction}

Addiction is a disorder characterized by persistent and compulsive dependence on a substance [43]. An addicted individual is afflicted by abnormal mental and physical activities that revolve around the recurrent and uncontrollable urge to seek and use a substance [44]. Causes of addiction vary considerably and remain poorly understood. Nevertheless, it has been suggested that neuroinflammation may play a role in the pathophysiology of addiction [45].

Psychostimulants induce microglial activation and pro-inflammatory cytokine expression. For example, methamphetamine increases the expression of TNF- $\alpha$ in mice [46] and the expression of IL-1 $\beta$ mRNA in human JAR choriocarcinoma cells [47]. Alcohol abuse is considered a source of microglial activation leading to the elevation of TNF- $\alpha$, IL- $1 \beta$, and IL- 6 levels in the brains of rats after chronic alcohol consumption, resulting in neurodegeneration and deterioration of memory and learning processes [48]. Moreover, methamphetamine increases IL- 6 and TNF- $\alpha$ levels in cultures of rat microglial cells, resulting in microglial cell apoptosis [49].

\section{Schizophrenia}

Schizophrenia is a chronic and debilitating disorder with positive and negative symptoms. Positive symptoms are characterized by the presence of abnormal feelings or behaviors including hallucinations and delusions, while negative symptoms are characterized by lack of interest and indifference in daily life [6]. Two major hypotheses have been established to explain the etiology of schizophrenia: the dopamine dysfunction hypothesis and the glutamatergic hypofunction hypothesis [50]. More recently, neuroinflammation has been suggested as a cause of schizophrenia [51]. Supporting this hypothesis, increased cytokine levels have been associated with schizophrenia [6]. More specifically, it has been reported that schizophrenia patients have high levels of pro-inflammatory cytokines in cerebrospinal fluid [52]. IL-6 has been shown to play a central role in the neuronal reaction to nerve injury and is involved in microglial and astrocytic activation [53], and TNF- $\alpha$, produced by lipopolysaccharide-stimulated microglia, is necessary and sufficient to trigger apoptosis in mouse neural precursor cells [54]. Furthermore, activated microglia release pro-inflammatory cytokines such as IL-1 $\beta$, IL- 6 , and TNF- $\alpha$, leading to neurodegeneration through neuroinflammation. Therefore, the neuroinflammatory process may be associated with schizophrenia.

\section{CONCLUSION}

In conclusion, several studies have shown the potential role of microglial activation pathways related to CNS neuroinflamma- 
tion in neurodegenerative diseases and psychiatric disorders. A combined dysregulation of microglial activation and pro-inflammatory cytokine production may be an important driver in the pathogenesis of these diseases, as they are associated with neuroimmunological abnormalities contributing to neurodegeneration. Further studies are needed to investigate the detailed mechanisms of microglial activation in the neuroinflammatory process and the subsequent onset of disease.

\section{REFERENCES}

1. Onore C, Careaga M, Ashwood P. The role of immune dysfunction in the pathophysiology of autism. Brain Behav Immun 2012;26: 383-92.

2. Theoharides TC, Asadi S, Patel AB. Focal brain inflammation and autism. J Neuroinflammation 2013;10:46.

3. Theoharides TC, Zhang B. Neuro-inflammation, blood-brain barrier, seizures and autism. J Neuroinflammation 2011;8:168.

4. Najjar S, Pearlman DM, Alper K, Najjar A, Devinsky O. Neuroinflammation and psychiatric illness. J Neuroinflammation 2013;10: 43.

5. Stertz L, Magalhães PV, Kapczinski F. Is bipolar disorder an inflammatory condition? The relevance of microglial activation. Curr Opin Psychiatry 2013;26:19-26.

6. Réus GZ, Fries GR, Stertz L, Badawy M, Passos IC, Barichello T, et al. The role of inflammation and microglial activation in the pathophysiology of psychiatric disorders. Neuroscience 2015;300:141-54.

7. Zhao Q, Peng C, Wu X, Chen Y, Wang C, You Z. Maternal sleep deprivation inhibits hippocampal neurogenesis associated with inflammatory response in young offspring rats. Neurobiol Dis 2014; 68:57-65.

8. Prince M, Wimo A, Guerchet M, Ali GC, Wu YT, Prina M. World alzheimer report 2015: the global impact of dementia. An analysis of prevalence, incid ence, cost and trends. London: Alzheimer's Disease International; 2015.

9. Murphy MP, LeVine H III. Alzheimer's disease and the $\beta$-amyloid peptide. J Alzheimers Dis 2010;19:311.

10. Heneka MT, Kummer MP, Latz E. Innate immune activation in neurodegenerative disease. Nat Rev Immunol 2014;14:463-77.

11. Norden DM, Muccigrosso MM, Godbout JP. Microglial priming and enhanced reactivity to secondary insult in aging, and traumatic CNS injury, and neurodegenerative disease. Neuropharmacology 2015;96(Pt A):29-41.

12. Jack CR Jr, Knopman DS, Jagust WJ, Shaw LM, Aisen PS, Weiner MW, et al. Hypothetical model of dynamic biomarkers of the Al- zheimer's pathological cascade. Lancet Neurol 2010;9:119-28.

13. Sperling RA, Aisen PS, Beckett LA, Bennett DA, Craft S, Fagan $\mathrm{AM}$, et al. Toward defining the preclinical stages of Alzheimer's disease: recommendations from the National Institute on AgingAlzheimer's Association workgroups on diagnostic guidelines for Alzheimer's disease. Alzheimers Dement 2011;7:280-92.

14. Wirth M, Madison CM, Rabinovici GD, Oh H, Landau SM, Jagust WJ. Alzheimer's disease neurodegenerative biomarkers are associated with decreased cognitive function but not $\beta$-amyloid in cognitively normal older individuals. J Neurosci 2013;33:5553-63.

15. Steiner N, Balez R, Karunaweera N, Lind JM, Munch G, Ooi L. Neuroprotection of Neuro2a cells and the cytokine suppressive and anti-inflammatory mode of action of resveratrol in activated RAW264.7 macrophages and C8-B4 microglia. Neurochem Int 2015;95:46-54.

16. Fahn S. Description of Parkinson's disease as a clinical syndrome. Ann N Y Acad Sci 2003;991:1-14.

17. Waak J, Weber SS, Waldenmaier A, Gorner K, Alunni-Fabbroni M, Schell $\mathrm{H}$, et al. Regulation of astrocyte inflammatory responses by the Parkinson's disease-associated gene DJ-1. FASEB J 2009;23: 2478-89.

18. Wang Q, Liu Y, Zhou J. Neuroinflammation in Parkinson's disease and its potential as therapeutic target. Transl Neurodegener 2015; 4:19.

19. Wirdefeldt K, Adami HO, Cole P, Trichopoulos D, Mandel J. Epidemiology and etiology of Parkinson's disease: a review of the evidence. Eur J Epidemiol 2011;26 Suppl 1:S1-58.

20. Hirsch EC, Vyas S, Hunot S. Neuroinflammation in Parkinson's disease. Parkinsonism Relat Disord 2012;18 Suppl 1:S210-2.

21. Cagnin A, Kassiou M, Meikle SR, Banati RB. In vivo evidence for microglial activation in neurodegenerative dementia. Acta Neurol Scand Suppl 2006;185:107-14.

22. Ferrari CC, Pott Godoy MC, Tarelli R, Chertoff M, Depino AM, Pitossi FJ. Progressive neurodegeneration and motor disabilities induced by chronic expression of IL-1beta in the substantia nigra. Neurobiol Dis 2006;24:183-93.

23. World Health Organization. Media Centre. Depression. Fact Sheet No.369 2015 [Internet]. Geneva: World Health Organization; c2016 [cited 2016 May 9]. Available from: http://www.who.int/mediacentre/ factsheets/fs369/en/.

24. Ceretta LB, Reus GZ, Abelaira HM, Jornada LK, Schwalm MT, Hoepers NJ, et al. Increased prevalence of mood disorders and suicidal ideation in type 2 diabetic patients. Acta Diabetol 2012;49 Suppl 1:S227-34.

25. Howren MB, Lamkin DM, Suls J. Associations of depression with 
C-reactive protein, IL-1, and IL-6: a meta-analysis. Psychosom Med 2009;71:171-86.

26. Dowlati Y, Herrmann N, Swardfager W, Liu H, Sham L, Reim EK, et al. A meta-analysis of cytokines in major depression. Biol Psychiatry 2010;67:446-57.

27. Miller AH, Maletic V, Raison CL. Inflammation and its discontents: the role of cytokines in the pathophysiology of major depression. Biol Psychiatry 2009;65:732-41.

28. Frick LR, Williams K, Pittenger C. Microglial dysregulation in psychiatric disease. Clin Dev Immunol 2013;2013:608654.

29. Tynan RJ, Beynon SB, Hinwood M, Johnson SJ, Nilsson M, Woods JJ, et al. Chronic stress-induced disruption of the astrocyte network is driven by structural atrophy and not loss of astrocytes. Acta Neuropathol 2013;126:75-91.

30. Couch Y, Anthony DC, Dolgov O, Revischin A, Festoff B, Santos AI, et al. Microglial activation, increased TNF and SERT expression in the prefrontal cortex define stress-altered behaviour in mice susceptible to anhedonia. Brain Behav Immun 2013;29:136-46.

31. Frank MG, Baratta MV, Sprunger DB, Watkins LR, Maier SF. Microglia serve as a neuroimmune substrate for stress-induced potentiation of CNS pro-inflammatory cytokine responses. Brain Behav Immun 2007;21:47-59.

32. Diz-Chaves Y, Pernía O, Carrero P, Garcia-Segura LM. Prenatal stress causes alterations in the morphology of microglia and the inflammatory response of the hippocampus of adult female mice. J Neuroinflammation 2012;9:71.

33. Ohgi Y, Futamura T, Kikuchi T, Hashimoto K. Effects of antidepressants on alternations in serum cytokines and depressive-like behavior in mice after lipopolysaccharide administration. Pharmacol Biochem Behav 2013;103:853-9.

34. Tynan RJ, Weidenhofer J, Hinwood M, Cairns MJ, Day TA, Walker FR. A comparative examination of the anti-inflammatory effects of SSRI and SNRI antidepressants on LPS stimulated microglia. Brain Behav Immun 2012;26:469-79.

35. Serafini G, Rihmer Z, Amore M. The role glutamate excitotoxicity and neuroinflammation in depression and suicidal behavior: focus on microglia cells. Neuroimmunol Neuroinflamm 2015;2:127-30.

36. Theoharides TC, Angelidou A, Alysandratos KD, Zhang B, Asadi S, Francis $\mathrm{K}$, et al. Mast cell activation and autism. Biochim Biophys Acta 2012;1822:34-41.

37. Morgan JT, Chana G, Abramson I, Semendeferi K, Courchesne E, Everall IP. Abnormal microglial-neuronal spatial organization in the dorsolateral prefrontal cortex in autism. Brain Res 2012;1456: $72-81$.

38. Tetreault NA, Hakeem AY, Jiang S, Williams BA, Allman E, Wold
BJ, et al. Microglia in the cerebral cortex in autism. J Autism Dev Disord 2012;42:2569-84.

39. Suzuki K, Sugihara G, Ouchi Y, Nakamura K, Futatsubashi M, Takebayashi K, et al. Microglial activation in young adults with autism spectrum disorder. JAMA Psychiatry 2013;70:49-58.

40. Lee KP, Sudjarwo GW, Kim JS, Dirgantara S, Maeng WJ, Hong H. The anti-inflammatory effect of Indonesian Areca catechu leaf extract in vitro and in vivo. Nutr Res Pract 2014;8:267-71.

41. Le Belle JE, Sperry J, Ngo A, Ghochani Y, Laks DR, López-Aranda $\mathrm{M}$, et al. Maternal inflammation contributes to brain overgrowth and autism-associated behaviors through altered redox signaling in stem and progenitor cells. Stem Cell Reports 2014;3:725-34.

42. Hornig M, Weissenböck H, Horscroft N, Lipkin WI. An infectionbased model of neurodevelopmental damage. Proc Natl Acad Sci U S A 1999;96:12102-7.

43. Koob GF, Volkow ND. Neurocircuitry of addiction. Neuropsychopharmacology 2010;35:217-38.

44. Leshner AI. Addiction is a brain disease, and it matters. Science 1997;278:45-7.

45. Rodrigues LC, Gobira PH, de Oliveira AC, Pelicao R, Teixeira AL, Moreira FA, et al. Neuroinflammation as a possible link between cannabinoids and addiction. Acta Neuropsychiatr 2014;26:334-46.

46. Sadasivan S, Pond BB, Pani AK, Qu C, Jiao Y, Smeyne RJ. Methylphenidate exposure induces dopamine neuron loss and activation of microglia in the basal ganglia of mice. PLoS One 2012;7:e33693.

47. Nakajima A, Yamada K, Nagai T, Uchiyama T, Miyamoto Y, Mamiya $\mathrm{T}$, et al. Role of tumor necrosis factor-alpha in methamphetamine-induced drug dependence and neurotoxicity. J Neurosci 2004;24:2212-25.

48. Zhao YN, Wang F, Fan YX, Ping GF, Yang JY, Wu CF. Activated microglia are implicated in cognitive deficits, neuronal death, and successful recovery following intermittent ethanol exposure. Behav Brain Res 2013;236:270-82.

49. Wang J, Qian W, Liu J, Zhao J, Yu P, Jiang L, et al. Effect of Methamphetamine on the microglial damage: role of potassium channel Kv1.3. PLoS One 2014;9:e88642.

50. Meyer U. Developmental neuroinflammation and schizophrenia. Progr Neuropsychopharmacol Biol Psychiatry 2013;42:20-34.

51. Monji A, Kato T, Kanba S. Cytokines and schizophrenia: microglia hypothesis of schizophrenia. Psychiatry Clin Neurosci 2009;63:25765.

52. Muller N, Weidinger E, Leitner B, Schwarz M). The role of inflammation in schizophrenia. Front Neurosci 2015;9:372.

53. Erta M, Quintana A, Hdalgo J. Interleukin-6, a major cytokine in the central nervous system. Int J Bio Sci 2012;8:1254-66. 
54. Guadagno J, Xu X, Karajgikar M, Brown A, Cregan SP. Microgliaderived TNFa induces apoptosis in neural precursor cells via tran- scriptional activation of the Bcl-2 family member Puma. Cell Death Dis 2013;4,e538. 